\title{
Numerical analysis of surrounding environment deformation caused by excavation of foundation pit
}

\author{
Jingde Liu \\ Shanghai Shen Yuan Geotechnical Engineering Co. Ltd., Shanghai 200040, China \\ liu-jd03@126.com
}

\begin{abstract}
Keywords: foundation pit excavation, environment influence, numerical analysis, hardening soil model

Abstract. The environment deformation caused by the excavation of a foundation pit is numerical analyzed using the hardening soil model. The simulation results show that the deformations of supporting structures of this foundation pit and the surrounding environment can meet the requirements of deformation control. The retaining structure design of this foundation pit project can ensure the safety of the project itself and the serviceability of the surrounding buildings or structures.
\end{abstract}

\section{Introduction}

The construction scale of foundation pit project gets greater and greater with the steady growth of economics. Moreover, the foundation pits are often adjacent to sensitive buildings or structures, such as municipal pipelines, subway tunnels and old buildings. Under such condition, besides ensuring the safety of the foundation pit project, the deformation caused by foundation pit excavation must be carefully controlled. This makes it necessary to analyze the environment influence of the excavation of foundation pit. Due to the complexity of foundation pit project, traditional method cannot rationally carry out such work. Alternatively, numerical analysis becomes an efficient method to analyses the environment influence of foundation pit excavation because of its advantage of considering the geological condition, distribution of struts system, construction process and the influence of adjacent buildings or structures.

The key problem of numerical analysis of foundation pit project lies on the choice of the constitutive model of soils. Among these well-known constitutive model, such as Mohr-Coulomb model, Hardening Soil model ${ }^{[1]}$, Drucker-Prager model and Cam Clay model, the Hardening Soil model can take into account the hardening property of soil and the dependence of the mechanical behaviors of soil on stress history and stress path ${ }^{[2]}$. Hence, the Hardening Soil model can rationally simulate the deformation of retaining wall and the movements of surrounding soil and buildings ${ }^{[3-5]}$.

This paper presents the numerical analysis of surrounding environment influences caused by the excavation of a foundation pit. The deformation of several municipal pipelines and an old building with shallow foundation are specifically studied to check whether or not the excavation support structure meets the requirement of deformation control.

\section{The Hardening Soil model}

Overview of the hardening soil model. The hardening soil model is proposed based on the classical elasto-plasticity theory to simulate the nonlinear, inelastic and stress dependent behavior of soils. The hardening soil model assumes that soils yield due to both shear stress and mean effective stress. Thus it adopts the Mohr-Coulomb failure criterion.

$$
\left(\sigma_{1}-\sigma_{3}\right)_{f}=2\left(c^{\prime} \cos \varphi^{\prime}+\sigma^{\prime}{ }_{3} \sin \varphi^{\prime}\right) /\left(1-\sin \varphi^{\prime}\right)
$$

The model employs two functions to simulate the yielding due to shear stress and mean effective stress, which are given as Eq. (2) and (3), respectively. 


$$
\begin{aligned}
& f_{s}=\frac{q_{u}}{E_{50}} \frac{q}{q_{u}-q}-\frac{2 q}{E_{u r}}-\gamma^{p} \\
& f_{c}=\frac{q^{2}}{\left[6 \sin \varphi^{\prime} /\left(3-\sin \varphi^{\prime}\right)\right]^{2}}-p^{2}-p_{c}^{2}
\end{aligned}
$$

Under a given increment of shear stress, the plastic shear strain increment can be obtained from Eq. (2) and the corresponding plastic volumetric strain can be obtained from the flow rule expressed in Eq. (4). Under a given increment of mean effective stress, the plastic volumetric strain increment can be obtained from the hardening law given in Eq. (5).

$$
\begin{aligned}
& \Delta \varepsilon_{v}^{p}=\sin \psi \Delta \gamma^{p} \\
& \Delta \varepsilon_{v}^{p}=\Delta p / K_{c}-\Delta p / K_{s}
\end{aligned}
$$

where $K_{c}$ and $K_{s}$ are related to the modulus of $E_{u r}^{\text {ref }}$ and $E_{\text {oed }}^{\text {ref }}$ and the coefficient of earth pressure $\mathrm{k}_{0}$.

Model parameters. The hardening soil model includes a total of nine parameters which is listed in Table. 1. Most of these soil parameters can be determined from oedometer consolidation test and consolidated drained triaxial compression test (CD). If the consolidation test is absent, the parameter $E_{\text {oed }}^{\text {ref }}$ can be set equal to $E_{50}^{\text {ref }}$. If the unloading-reloading cycle is not performed in the CD test, the parameter $E_{u r}^{r e f}$ can be set as three times $E_{50}^{\text {ref }}$.

Once the parameters in Table 1 has been determined, the modulus of soil under any stress condition can be computed using the following equations.

$$
\begin{aligned}
& E_{50}=E_{50}^{r e f}\left[\left(c^{\prime} \cos \varphi^{\prime}+\sigma_{3}^{\prime} \sin \varphi^{\prime}\right) /\left(c^{\prime} \cos \varphi^{\prime}+p^{r e f} \sin \varphi^{\prime}\right)\right]^{m} \\
& E_{u r}=E_{u r}^{r e f}\left[\left(c^{\prime} \cos \varphi^{\prime}+\sigma_{3}^{\prime} \sin \varphi^{\prime}\right) /\left(c^{\prime} \cos \varphi^{\prime}+p^{r e f} \sin \varphi^{\prime}\right)\right]^{m} \\
& E_{\text {oed }}=E_{\text {oed }}^{r e f}\left[\left(c^{\prime} \cos \varphi^{\prime}+\sigma_{3}^{\prime} \sin \varphi^{\prime}\right) /\left(c^{\prime} \cos \varphi^{\prime}+p^{r e f} \sin \varphi^{\prime}\right)\right]^{m}
\end{aligned}
$$

Table 1 Parameters for the hardening soil model

\begin{tabular}{c|c|c|c}
\hline Parameter & Description & Parameter & Description \\
\hline $\mathrm{c}^{\prime}$ & Effective apparent cohesion & $\varphi^{\prime}$ & Effective peak friction angel \\
\hline $\mathrm{E}_{50}{ }^{\text {ref }}$ & $\begin{array}{c}\text { Secant modulus at confining } \\
\text { stress of } 100 \mathrm{kPa}\end{array}$ & $\mathrm{E}_{\text {oed }}{ }^{\text {ref }}$ & $\begin{array}{c}\text { 1-D compression modulus under } \\
\text { the vertical stress of 100 kPa }\end{array}$ \\
\hline $\mathrm{E}_{\mathrm{ur}}{ }^{\text {ref }}$ & $\begin{array}{c}\text { Unloading-reloading modulus at } \\
\text { confining stress of } 100 \mathrm{kPa}\end{array}$ & $m$ & $\begin{array}{c}\text { Exponent controlling the } \\
\text { stress-dependency of modulus }\end{array}$ \\
\hline$\psi$ & Dilation angle & $\mathrm{k}_{0}$ & Coefficient of earth pressure \\
\hline$v$ & Poisson's ratio & & \\
\hline
\end{tabular}

\section{Numerical analysis of environment influence of a foundation pit project}

Project condition. The foundation pit project is constructed for a two-storeyed basement. The common excavation depth of the foundation pit is $10.4 \mathrm{~m}$ and the greatest excavation depth is about $12.7 \mathrm{~m}$. There are several pipelines for gas, water supply and sewage in north of the foundation pit. The distance between these pipelines and the excavation boundary ranges from $5.8 \mathrm{~m}$ to $14.7 \mathrm{~m}$. There are three six-storeyed residential buildings with shallow foundations lie in east of the foundation pit. The minimum distance between these buildings and the excavation boundary is about 10.8. Since the municipal pipelines and the residential buildings locate within the region twice of the excavation depth, 
the surrounding environment of this foundation project is quite sensitive and thus special attention needs to be paid in the retaining design to control the deformation caused by excavation.

To ensure the safety of the foundation pit project, the contiguous bored piles with two layers concrete strut are design to form the retaining structure of this foundation pit project. The diameter of the bored piles is chosen as $0.9 \mathrm{~m}$. The sectional dimension is $1200 \times 800 \mathrm{~mm}$ and $1300 \times 800 \mathrm{~mm}$ the first and the second supporting enclosing purlin. The sectional dimension is $900 \times 800 \mathrm{~mm}$ and $1000 \times 800 \mathrm{~mm}$ for the first and the second layer strut respectively. The vertical distance between the two layers concrete strut is $5.5 \mathrm{~m}$.

Numerical model. Two-dimensional models of two sections are developed to simulate the environmental deformation due to the construction of foundation pit, as displayed in Figure 1. The soils are simulated using solid instance. The piles and the residential buildings are simulated using plate element. The pipelines are simulated using tunnel element. Goodman contact element is used to describe the contact behaviors between underground structures and soils. In the numerical analysis, the excavation depth is set as $12.7 \mathrm{~m}$.
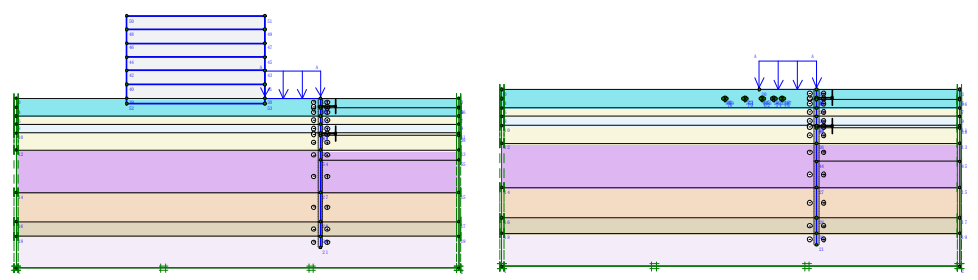

Figure 1 Numerical model of two sections for the excavation of foundation pit.

Table 2 lists the parameters for the hardening soil model of various soil layers of this foundation pit project. For all soil layers, parameter $E_{u r}^{r e f}$ is set as three times $E_{50}^{\text {ref }}$; parameter $m$ is set as 0.8 ; dilation angle is set as 0 ; poisson's ratio is set as 0.3 ; the coefficient of earth pressure is set equal to 1 -sin $\varphi$ '.

Table 2 Parameters for hardening soil model of various soil layers

\begin{tabular}{c|c|c|c|c}
\hline Soil layer & $E_{50}^{\text {ref }}$ & $E_{\text {oed }}^{\text {ref }}$ & $\mathrm{c}^{\prime}$ & $\varphi^{\prime}$ \\
\hline clay & 3.4 & 4.4 & 10.0 & 25.2 \\
\hline mucky silty clay & 1.2 & 1.6 & 10.0 & 20.1 \\
\hline nucky clay & 1.9 & 2.0 & 3.0 & 27.3 \\
\hline silty clay & 6.1 & 5.5 & 20.0 & 26.7 \\
\hline silty clay & 6.9 & 6.1 & 22.0 & 28.5 \\
\hline
\end{tabular}
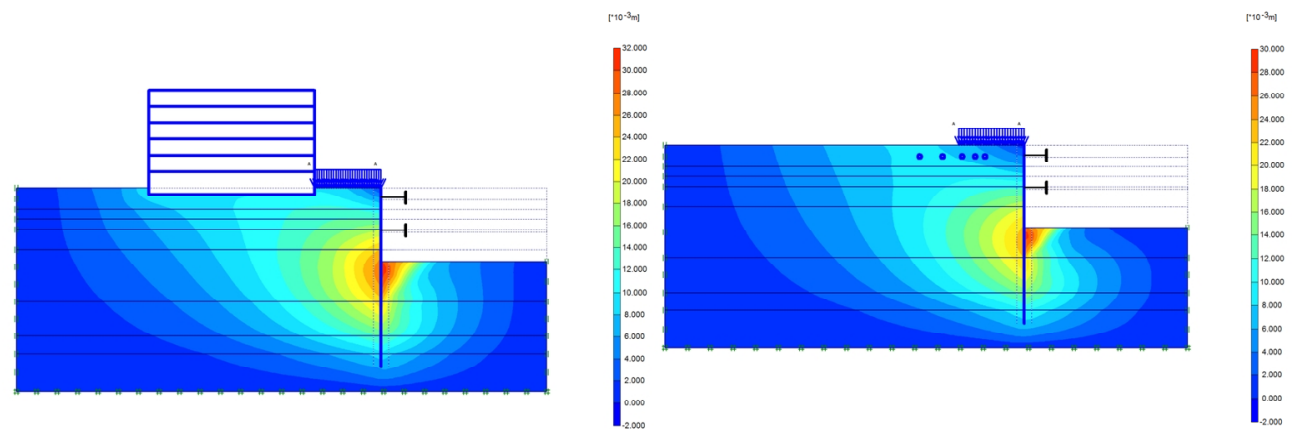

Figure 2 Horizontal displacements of two sections.

Simulation results. Figure 2 presents the horizontal displacements of soils and structures. It is shown that: (i) the greatest horizontal displacement occurs at the excavation surface and the deformation modes of both sections are similar; (ii) Soils within the region that is about three to four times the excavation depth behind the retaining piles experience notable horizontal displacement; (iii) the horizontal displacements of the top of retaining piles are rather small due to the rigidity and great 
siffness of the strut. The maximum displacement of the piles is no more than $32 \mathrm{~mm}$, indicating that the adopted retaining structure is safe for the foundation project itself.
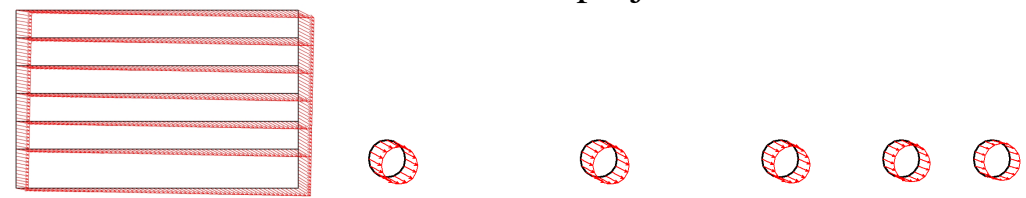

Figure 3 Maximum deformation of surrounding buildings of two sections.

Table 3 Maximum displacement of buildings and pipelines

\begin{tabular}{c|c|c|c|c}
\hline \multirow{2}{*}{$\begin{array}{c}\text { Structure } \\
\text { type }\end{array}$} & Distance from pit boundary $(\mathrm{m})$ & \multicolumn{3}{|c}{ Maximum displacement $(\mathrm{mm})$} \\
\cline { 3 - 5 } & 10.8 & Horizontal & Vertical & Total \\
\hline Building & $5.8 \sim 14.7$ & 12.17 & 5.97 & 13.56 \\
\hline Pipelines & 8.39 & 4.4 & 9.44 \\
\hline
\end{tabular}

Figure 3 and Table 3 presents the maximum deformation of surrounding buildings of two sections. It is shown that: (i) all the surrounding buildings experience displacement towards the foundation pit due to the unbalanced lateral earth pressure caused by excavation; (ii) the maximum displacements of the residential buildings and the municipal pipelines are $13.56 \mathrm{~mm}$ and $9.44 \mathrm{~mm}$ respectively, meeting the requirement of deformation control. This indicates that the retaining structure adopted is efficient to keep the surrounding buildings and municipal pilelines safe.

\section{Conclusions}

By using the hardening soil model, the construction process of a foundation pit is simulated and the environmental influence is numerical analyzed. The simulation results show that the deformation of the retaining structures and the surrounding residential buildings and municipal pipelines can meet the requirement of deformation control. The retaining structure design of this foundation pit can ensure the safety of the project itself and the serviceablity of the surrounding buildings and pipelines.

\section{Acknowledgements}

This work was funded by the Excellent Technical Leader Program of Shanghai (NO.14XD1420400) and Excellent Youth Foundation of Xian Dai Architectural Design Co., Ltd. (NO.14-I-0015-JI).

\section{References}

[1] T. Schanz, P.A. Vermeer, P.G. Bonnier. The Hardening soil model: formulation and verification. Beyond 2000 in Computational Geotechnics - 10 years of Plaxis, Amsterdam 1999, p. 281-296.

[2] P.L. Teo, K.S. Wong. Application of the hardening soil model in deep excavation analysis. The IES Journal Part A: Civil \& Structural Engeering Vol. 5 (2012), p. 152-165.

[3] W.D. Wang, H.R. Wang, Z.H. Xu. Experimental study of parameters of hardening soil model for numerical analysis of excavations of foundation pits. Rock and Soil Mechnics Vol. 33 (2012), p. 2283-2290.

[4] S.B. Liu, C.B. Wang, L.B. Zhou, Z.C. Tang. Application and analysis of hardening soil model in deep foundation pits in Wuxi district. Chinese Journal of Rock Mechanics and Engineering Vol. 33 (2014), p. 3022-3028.

[5] X.L. Feng, Z.H. Xiong, Y. Mo, J.C. Pang. Numerical simulation and analysis of surrounding environment deformation influenced by excavation of foundation pits under complex conditions, Chinses Journal of Geotechnical Engineering Vol. 36 (2014), p. 330-336. 